\title{
The Regulation Analysis of Low-Carbon Orientation for China Land Use
}

\author{
Bikai Gong and Bing Chen \\ Institute of Land Reclamation and Ecological Restoration, \\ China University of Mining and Technology (Beijing); \\ Engineering Research Center of Mining Environment \& Ecological Safety, \\ Ministry of Education, 100083 Beijing, China \\ 191979032 @qq. com
}

\begin{abstract}
Greenhouse gas emission reduction has become the responsibility and consensus of all mankind's development, the way of non-sustainable land use results in a lot of greenhouse gas emissions in the context of low-carbon economy. On the basis of revealing impact of land use on carbon emissions and status of carbon emissions, this paper proposes the regulation proposals of land use based on low-carbon emission: make carbon emission's list of land use, optimize land use structure and layout, and strengthen land use control, intensive land use, soil and water conservation and ecological protection, management of agricultural land, woodland, grassland and wetland, control the scale of construction land and pace of expansion, establish compensation mechanism of land ecology. The research has great significance for China forming and further improving the policy system of land use of low-carbon emission.
\end{abstract}

Keywords: land use; low-carbon economy; regulation; China.

\section{Introduction}

"Our future energy - creating low-carbon economy" of the British Government in 2003 first proposed the concept of low-carbon economy, the core idea is to obtain more economic output with less energy consumption[1]. Then low-carbon economy attracted international attention, it advocates resource conservation, friendly environment and sustainable development, and reduces high-carbon energy consumption of coal, petroleum and others possibly, improve energy efficiency substantially, large-scale utilize renewable and low-carbon energy, large-scale develop emission reduction technology of greenhouse gas, build low-carbon society and maintain ecological balance. The development of low-carbon economy is global revolution involved in mode of production, lifestyle, values, national interests and human destiny, as well as an inevitable choice of the global economy being transferred from high-carbon energy into low-carbon energy[2, 3].

The development of low-carbon economy is not only a global effective way to climate warming, but also an inevitable choice of China saving energy, reducing emission and participating in international cooperation. China is in period of rapidly developing industrialization and urbanization, the coal -dominated energy structure 
results in China's emission of carbon dioxide in the forefront of the world. In 19992003, the emission of carbon dioxide increased by 170 million tons, and China has become the world's second largest emission country[4]. On the research of lowcarbon economy, some China scholars proposed many useful ideas. Zhuang Guiyang showed that the essence of low-carbon economy is the problem of high-energy efficiency and clean energy structure, the core is the innovation of energy technology and system[5]. Zhang Kunmin analyzed the facing challenge of China developing low-carbon economy from the view of energy, and thought energy strategy of supporting sustainable economic and social development needs to be build[6, 7]. Xia Kunbao showed that low-carbon economy is the only way to achieve sustainable urban development; it needs to carry out mode of low-carbon production and consumption, and greatly develop circular economy and clean production[8].

Low-carbon economy seems to be the problem of environmental technology's application and industrial structure's optimization, but the problem of land use essentially. China has been concerned about impact of land use on global change for a long time, and proposed policy advice on the regulation of land use based on impact of land use on carbon emissions and status of carbon emissions. Conventional regulated policies of low-carbon, with the use of policies of land use structural optimization, and the introduction of regulated measures of land use, have a great significance of China performing and successfully achieving the promise of voluntary emission reduction.

\section{Impact of Land Use on Carbon Emissions}

Glaeser and Kahn analyzed the relationship between carbon emissions and land use, and thought constrains on land use are more strict, carbon emissions' level of the residents living are lower[9]. The change of land use is an important uncertainty factor in the estimates of carbon emission. On the one hand, the change of land use changes the types of ecosystem directly, and then changes the net primary productivity of ecosystem and their inputs of soil organic carbon; on the other hand, the change of land use changes soil physical and chemical properties potentially, and then changes soil respiration's sensitivity coefficient to temperature changes.

Land use plays an important role in increasing global atmospheric carbon dioxide, and China's change of land use has great impacts on carbon emission of terrestrial ecosystem. The way of long-term non-sustainable land use (deforestation, reclamation of grassland, transformation of marshes, etc.) results in the release of carbon from terrestrial ecosystem, and becomes one of the main reason of atmospheric carbon dioxide rising, only second to fossil fuel burning. According to the calculations of the World Resource Organization and well-known experts on the carbon cycle, in the global carbon emissions from 1850 to 1998, land use change and its carbon emissions accounted for $1 / 3$ of the total emissions of human activities affect; while the cumulative carbon emissions of the whole country's land use change were $10.6 \mathrm{PgC}$ from 1950 to 2005, accounting for $30 \%$ of the total artificial carbon source emissions, as well as $12 \%$ of carbon emissions of global land use change at the same period[10].

There are direct and indirect carbon emissions from the classification of carbon emissions of land use. Direct carbon emissions can also be subdivided into carbon 
emissions of changed and maintained land use types. The former refers that the change of land use or cover type results in carbon emissions caused by the change of ecosystem type, such as deforestation, reclaiming land from lakes, construction land expansion and so on; the latter refers to carbon emissions driven by the change of land management and carbon sink of ecosystem, including farming, grassland degradation, nutrient input and changes of cropping systems. Indirect carbon emissions mainly refer to all man-made carbon source emissions carried on each type of land use, including the heating of neighborhood, exhaust from traffic land, and process emissions of mining land; they are spatial intensities and distributive effects of artificial carbon source emissions on the different land use types.

\section{The Status of Carbon Emission Reduction of Land Use}

In 2006, China's disposable energy consumption accounted for more than $16 \%$ of the world, and the emissions of carbon dioxide were more than $20 \%$ of the world, equal with per capita emissions in the world. This indicated that, in the process of industrialization and urbanization, the intensity of carbon emissions is a little high, while energy consumption will continue to grow, with not much room for carbon emissions. Describe the statue of carbon emissions of China's land use based on direct and indirect carbon emissions of land use, carbon emissions effect of land use types, and regional carbon emissions.

\subsection{Direct Carbon Emissions of Land Use}

From 1980 to 2005, terrestrial ecosystem has presented obvious carbon sinks, and the average annual level of carbon sinks were about 154 to 167 million tons of carbon. From the view of classification structure, vegetation and soil carbon pools both presented the functions of carbon sinks, the average annual carbon sinks of vegetation was 108 to 121 million tons, and the capacity of soil carbon sinks was weak with $1 / 3$ of vegetation carbon sinks. From the view of ecosystem types, the function of forest carbon sinks had the obvious effect on the whole terrestrial ecosystem, about 2/3 of the whole terrestrial ecosystem. From the view of spatial pattern, the carbon sinks of land use had more significant effect in east, south and north China, and there was more significant effect of carbon emissions of land use in northeast and southwest China, while there was less effect in northwest China.

\subsection{Indirect Carbon Emissions of Land Use}

Take the comprehensive level of carbon emissions of China's four departments in 1995 for an example, the total emissions of carbon dioxide were 2.642 billion tons, methane was 32 million tons, and the carbon dioxide equivalent was about 3.3 billion tons. In 2005, the total emissions of carbon dioxide were 5.55 billion tons, methane was 38 million tons, and the carbon dioxide equivalent was about 6.34 billion tons. In the 80th of last century, artificial source emissions were as 3 times as the storage of terrestrial ecosystem, but 10 times in 2005. Therefore, the increase of artificial resource carbon emissions was much faster than the promotion of carbon's absorptive capability of terrestrial ecosystem[10]. 


\subsection{Carbon Emission Effect of Land Use Types}

Without considering the situation of carbon's absorption, the general carbon emission intensity of agricultural land is 0.37 tons per hectare, below the international average level. The main reason is that China traditional agriculture paid attention to the use of organic fertilizer and straw, so the effect of organic carbon storage of agricultural soil was remarkable.

Forest is an important carbon sink, the carbon emission intensity is 0.06 tons per hectare and the carbon absorption intensity is 0.49 tons per hectare. Since the 70th or 80th of last century, the strong advocating of afforestation has resulted in forest volume rising, large young forest had obvious carbon absorption effect of growth, stronger than at the same period of timber harvesting, firewood collection, disaster interference and other effects.

For construction land, there were the highest volume and intensity of carbon emissions. The emission intensity of construction land was 55.8 tons per hectare in all. That means that there will be 149.8 times of carbon emission when transforming one hectare of agricultural land into construction land; while transforming one hectare of forest land into construction land, it will increase 929 times of carbon emissions. From the view of different regions, there were the highest carbon emission intensity of construction land in north and east China, about 81.2 tons per hectare and 65.3 tons per hectare; the general level in northeast, middle south and southwest China, about 48.8 tons per hectare, 46.5 tons per hectare and 49.1 tons per hectare; lower level in northwest China about 33.9 tons per hectare. In a word, there are greater carbon emissions of per unit area of construction land in areas of high levels of heavy industrialization and big population density. From the view of the internal structure of construction land, there was highest carbon emission intensity in industrial and mining land, about 196 tons per hectare; followed by traffic land, about 43.7 tons per hectare; the smallest was urban and rural residential land, only about 8.3 tons per hectare[10].

\subsection{Carbon Emissions of Regional Land Use}

As the world's major energy consumer, China's carbon emissions are not only reflected on volume's growth, but also spatial pattern change of carbon emissions. From the view of the change of large regional system, the carbon emissions in the east have dominated the country all the time; the proportion of central region's carbon emissions in the country showed the trend of flatting to down; and the proportion in the western region was small but basically maintained an upward trend[11]. Specifically as follows: there were high carbon emissions in most regions of east and north China, as well as Pearl River Delta, Yangtze River Delta, middle-south cities of northeast China and Chengdu-Chongqing Urban Agglomeration. There were lowcarbon emissions or carbon balances in northwest China and most of Qinghai-Tibet Plateau. While the main areas of carbon sinks were in most of southwest, middlesouth, southeast China, part of northeast China, and Tianshan-Qingling zones. Besides, the afforestation areas in north and part of northwest China had a positive effect of carbon sinks. 


\section{The Regulated Suggestions of Land Use on the Basis of Low-Carbon}

As the world's largest developing country, China's economic development rely on resources consumption of fossil energy greatly, that resulted in increased carbon emissions and heave environmental pollution, these issues have seriously affected the quality of economic growth and the sustainability of development. The economic and social development drove China's carbon emissions, but the policy of increasing sinks such as commonly ecological protection and afforestation had no significant influence on containing carbon emissions increase. While the potential of carbon emission reduction after the optimization of land use structure in low-carbon economic development and macro-control is $1 / 3$ of conventional low-carbon policy. China has been highly concerned about energy conservation and land use on the impact of global change, on the basis of revealing the effect mechanism of carbon emissions of land use, form land use structure and layout of low-carbon emissions though innovating techniques of land use planning. That had great significance for further improving the policies of carbon emission reduction, particularly forming China's policy system of land use of low-carbon emissions.

\subsection{Make the List of Carbon Emissions of Land Use}

At present, home and abroad related standard of calculating carbon emissions are mainly on the basis of "2006IPCC Guidelines for National Greenhouse gas inventories", and "Initial National Communication on Climate Change" based on the domestic status in 1994, recently the new "Second Communications on Climate Change" has not yet to be introduced. The above files or standards have been difficult to meet the actual demand of the land department making decision, so carbon emission analysis of land use fitting the situations need to be made according to China's unique classification system of land use, vegetation and soil.

Overall China natural and social-economic carbon emissions of land use for nearly 20years, form carbon emission lists of fitting land use and its vegetation characteristics, on line with the current classification system of land use, and develop appropriate standards, in order to provide theoretical basis for macroscopic policymaking department to carry out low-carbon land use plan.

\subsection{Establish Matchable System of Low-Carbon Land Use Policy}

Currently, developing low-carbon economy and taking the road of low-carbon ecology is an inevitable direction of transforming in many cities, especially resourcebased cities. In order to change the way of low-carbon land use and set up awareness of low-carbon land, China also needs to propose fitting matchable system of land use policy based on low carbon from two views of carbon emission reduction and increased carbon sinks. The policy of increased carbon sinks includes optimization of land use structure, water and soil conservation, ecological protection, and the management of forestland, farmland, grassland and wetland; the policy of carbon emission reduction includes optimization of land use structure, carbon emission reduction of agricultural land and construction land, mechanism's construction of land ecological compensation and others. 


\section{(1) Optimize the structure and layout of land use}

From the view of emission reduction of increased carbon sinks of various land management policy, there are greatest potential for carbon emission reduction of land use structure's optimization. Innovating planning techniques of land use can further optimize the structure and layout of land use. Restricting non-sustainable way of land use, increasing the scale of forest area, controlling the reduction of cultivated land, grassland, marsh, beach and the expansion of construction land, and promoting the transformation from unused land into woodland, grassland and cultivated land, will produce more positive effects for carbon storage of China ecosystem.

\section{(2) Strengthen land use control}

China has been in period of rapid development of industrialization and urbanization, large scale infrastructure construction should be carried out by the way of low power, high efficiency and low-carbon emissions. Many cities are in the time of rapidly expanding, necessary controls and regulations need to be carried out for development of urban traffic and urban land at the same time[12]. Use urban dynamic emulation analysis, and fully stimulate traffic distance and carbon emissions of different granting schemes in the supply of urban land, in order to achieve balanced distributions of all kinds of land in the urban and scientifically plan to reduce urban carbon emissions.

Besides, promote industrial low-carbon by the policy of supplying land. Through land participating in macro-control, strengthen land review, strictly control blind expansion of "three high" industries (high intensity of energy consumption, high carbon emissions, high pollution), and encourage the development of low-carbon industry. When increasing approvals of construction land, local government will give priority to protect industrial land of low-carbon economy, contain project sites of excess capacity and duplicate construction. Build cyclic economic parks and lowcarbon developed test areas of land use. Accelerate establishing demonstration industrial parks, industrial parks and economic development parks of energy-saving low-carbon. Overall urban and rural construction with the idea of low-carbon economy, and develop new characteristic industrialization and urbanization fitting local realities.

\section{(3) Strengthen the saving of intensive land use}

Strengthen the saving of intensive land use, reduce emission of architectures. The saving of intensive land use not only reduces the consumption of land resources directly, but also produces more advanced architecture models, more efficient operated ways and more scientific streaming configurations though being replaced by more abundant elements. These will reduce the output of energy consumption and carbon emission per unit.

\section{(4) Strengthen water and soil conservation and ecological protection}

In important areas, sensitive areas and ecologically fragile areas of affecting the national ecological security, strictly control land desertification and water and soil erosion, and strengthen water and soil conservation and ecological protection; in the desert and Gobi areas, speed up the greening process of land and afforestation, newly increase areas of planting forest and forest carbon sinks. 


\section{(5) Strengthen management of agricultural land}

Develop new agriculture of organic, ecology, and efficiency; reduce the use of chemical fertilizers and pesticides. The potential for carbon emission reduction of agricultural land's management can not be ignored. According to the study, the carbon sequestration capacity of agricultural soil has increased $0.014 \%$ per year in the last few years with the improvement of the quality of cultivated land. Deeply study the carbon sequestration of farmland ecosystem, mitigate climate changes through biological and ecological carbon sequestration. Optimize farming system, promote the use of organic fertilizers, and improve the content of organic matter in soil. Straw returning to field increase soil nutrients and reduce soil erosion by wind and water. With materials of livestock manure, crop straw and other agricultural organic wastes, relying on the technology of recycling economy, achieve the exchange of each agricultural by-products and recycling use of wastes, and turn organic wastes into resources.

\section{(6) Strengthen management of forestland, grassland and wetland}

The studies show that, forest vegetation is the most effective carbon sink in the earth, the annual net carbon uptake of the global average per hectare of forest vegetation is about 0.26 0.39t. Developing forestry is an important measure to develop low-carbon economy, plant trees and grasses, strengthen management of wetland, and expand carbon sinks. Since the 80 s of the $20^{\text {th }}$ century, due to the large scale of afforestation and returning farmland to forest, animal husbandry, and lakes, the level of carbon storage in terrestrial ecosystems has improved significantly, 1/4 1/3 of artificial carbon emissions at the same period were absorbed[10]. Deeply study the carbon sequestration of grassland and forest ecosystem, mitigate climate changes through biological and ecological sequestration. Since 1949, there have been great achievement of afforestation, but the existing level of forest's maintenance and management should be improved, in order to reach the maximize of making oxygen from forest. For the main content of afforestation, speed up the construction of ecological barriers, continue to promote the construction of shelterbelts of upper and middle yangtze river and three-north area, increase forest coverage, and improve territory virescence.

\section{(7) Control the scale of construction land and the speed of expansion}

The requirements of coordinating urbanization and low-carbon are defining the scale of construction land, spatial scope and expanded pace of the overall urban planning in the level of urban planning. And the space of construction land are divided through the analysis of eco-environment capacity and development space in the level of urban planning, including the balanced mold of the whole shape of low-carbon, dynamic balance of low-carbon land use, green system's design of low-carbon road and others[13].

\section{(8) Establish the mechanism of land ecological compensation}

The total values of land resources include not only economic value, but also ecological value and social value[14]. Land ecological compensation includes that the state could expropriate tax of environmental resources, in order to ensure the government provide public service functions of ecological products of land resources. Besides, people who suffers the loss or pays the economic costs because of public 
interests (ecological protection) should be given fair compensation. Through accurately measuring and calculating areas of land for different use, combining with other empirical data, ecological value formed by the status of land use can be calculated.

\section{References}

1. Zhang, Q., Ye, X.-p., Chen, G.-w.: Low-carbon urban planning:a new vision. City Planning Review 34(2), 13-18 (2010)

2. Zhang, G.-f., Liu, Q.-w.: A study on low carbon economy policy based on equity theory. China Coal 36(1), 6-8, 12 (2010)

3. Huang, W.-s.: On the low-carbon tourism and the creation of low carbon tourist attractions. Ecological Economy (11), 100-102 (2009)

4. The carbon emission report of world-bank[EB/OL], http://i.cn.yahoo.com/billasx/blog/p22/

5. Zhuang, G.-y.: The way and potential of China's low-carbon economy development. Studies in International Technology and Economy 8(3), 8-12 (2005)

6. Zhang, K.-m.: China's role,challenges and strategy for the low carbon world. China Population Resources and Environment 18(3), 1-7 (2008)

7. Zhang, K.-m.: Development of low-carbon economy is China's internal demand. Theoretical Horizon (2), 26-28 (2010)

8. Xia, K.-b.: Development of low-carbon economy,urban sustainable development. Environmental Protection (3), 33-35 (2008)

9. Glaeser Edward, L., Kahn Matthew, E.: The greenness of cities:carbon dioxide emissions and urban development. Journal of Urban Economics 67(3), 404-418 (2010)

10. Carbon emissions: issues of land use regulation and control[EB/OL] (December 25, 2009), http://www.mlr.gov.cn/tdsc/lltt/200912/t20091228_131048.htm

11. Lei, Z., Huang, Y.-x., Li, Y.-m., et al.: An investigation on spatial changing pattern of $\mathrm{co}_{2}$ emissions in China. Resources Science 32(2), 211-217 (2010)

12. Pan, H.-x.: Urban spatial structure towards low carbon:new urban transport and land use model. Urban Studies 17(1), 40-45 (2010)

13. Han, Q., Liu, H.-1.: Low-carbon eco-towns planning and research. Development of Small Cities \& Towns (12), 73-78 (2009)

14. Gong, B., Deng, L., Hu, Y., et al.: Study on ecosystem service and its value assessment of cultivated land of reservoir inundated - a case study of Huangjinping hydropower station. Resource Development \& Market 23(12), 1085-1088 (2007) 